\title{
Seal strength improvement of valve-regulated lead-acid (VRLA) battery
}

\author{
Warawut Kaewon, Napassavong Rojanarowan \\ ${ }^{12}$ Department of Industrial Engineering, Faculty of Engineering, Chulalongkorn University, Bangkok, Thailand.
}

\begin{abstract}
This research has two objectives. The first objective is to study the effect of assembly process factors on the seal strength of the VRLA battery. The second objective is to find the optimal setting of significant parameters to maximize the seal strength to reduce the defective rate from air leakage defect. This research applied the design of experiment (DOE) technique using the two-level full factorial design to screen out the factors and then used the face-centered central composite design to help find the relationship between the seal strength and the significant factors. It was found that the factors which significantly affect the seal strength were the stopper distance of the case, the stopper distance of the lid, and the melting time. The optimization technique helped determine that the machine setting should be at the stopper distance of the case at $34.97 \mathrm{~mm}$., the stopper distance of the lid at $77.95 \mathrm{~mm}$., and the melting time at 3.1 second to maximize the heat seal strength. After improvement, the defective rate from air leakage defect significantly decreased from $0.12 \%$ to $0.01 \%$.
\end{abstract}

Keywords: VRLA Battery, Design of experiment (DOE), Defective reduction, Seal strength

\section{INTRODUCTION}

A valve-regulated acid-lead (VRLA) battery is commonly used in automatic motorcycles. A major defect found in the assembly process of the VRLA battery was air leakage. The air leakage problem occurs when the seal strength between the battery case and the lid is too low. Thus, there is a need to understand the relationship between the assembly process factors and the seal strength. Then, the optimal levels of those factors should be found to help increase the seal strength and reduce the defectives from the air leakage problem. To determine this relationship, the experiments have to be performed efficiently. The design of experiment (DOE) technique is an appropriate tool for this purpose. After obtaining the experimental results, a statistical analysis and optimization technique are the main tools for testing the significance of factors and finding the optimal levels of those process factors.

\section{LITERATURE REVIEW}

Since the discovery of the lead-acid battery by Plante in 1859, there has been a continuous evolution of the battery including the valve-regulated lead-acid (VRLA) battery [1]. There were a replacement of early glass container or case by hard rubber and later by high impact Polypropylene (PP) [2]. The first commercial units were devised by Sonnenschein $\mathrm{GmbH}$ in the 1960s [3].

Polypropylene (PP) is one of the most common plastic used in the manufacturing of lead-acid battery cases and lids [4]. It has many desirable properties when compared to other thermoplastics. These properties are high melting point, low density, high tensile modulus, and low cost. However, PP has relatively low melt strength and exhibits no strain hardening behavior in the melt state due to its linear molecular structure [5].

A critical process during the manufacture of the battery is the heat sealing process, which helps the formation of a good bond between the PP plastic lid and case. The strength of the bond is determined by the tensile testing. A number of factors contribute to the strength of the seal. These factors include the extent of the stopper distance, the holding time against the heating plates and its temperature [6], [7]. There were some researches, which studied the effect of a degradation of virgin and recycled polypropylene on the seal strength of the lead acid battery cases. Moreover, there were many researches that improve the performance of the VRLA battery concerning with chemical and electrical properties such as the chemical composition of lead alloy, and the discharge capacity. However, there were a few researches that study the performance of the VRLA battery resulting from the factors in real production processes such as the assembly process. The machine setting during the assembly process has significant effect to VRLA battery defectives. The objective of this paper is to find out the significant assembly process factors and the best setting of those factors to increase the seal strength and then mitigate the problem of air leakage of the VRLA battery.

\section{PROBLEM DESCRIPTION}

In the case study factory, the major defect found in the assembly process was the air leakage. It was found that the proportion of defectives from air leakage is $0.12 \%$. The Pareto chart shown in Fig. 1 showed that 
the air leakage defect caused $71.9 \%$ of total defectives. The air leakage occurred in the heat sealing process, which connected the case to the lid. The air leakage was tested using the leak tester. The air leakage problem was related to the seal strength of the bond between the plastic case and the lid. The dot plot shown in Fig. 2 and the statistical t-test showed that the batteries that had air leakage defects had the lower seal strength than the normal batteries at the significance level of 0.05 . The means of the seal strength of normal batteries and batteries with air leakage were $2.85 \mathrm{~kg} . / \mathrm{mm}$. and $0.95 \mathrm{~kg} . / \mathrm{mm}$. respectively.

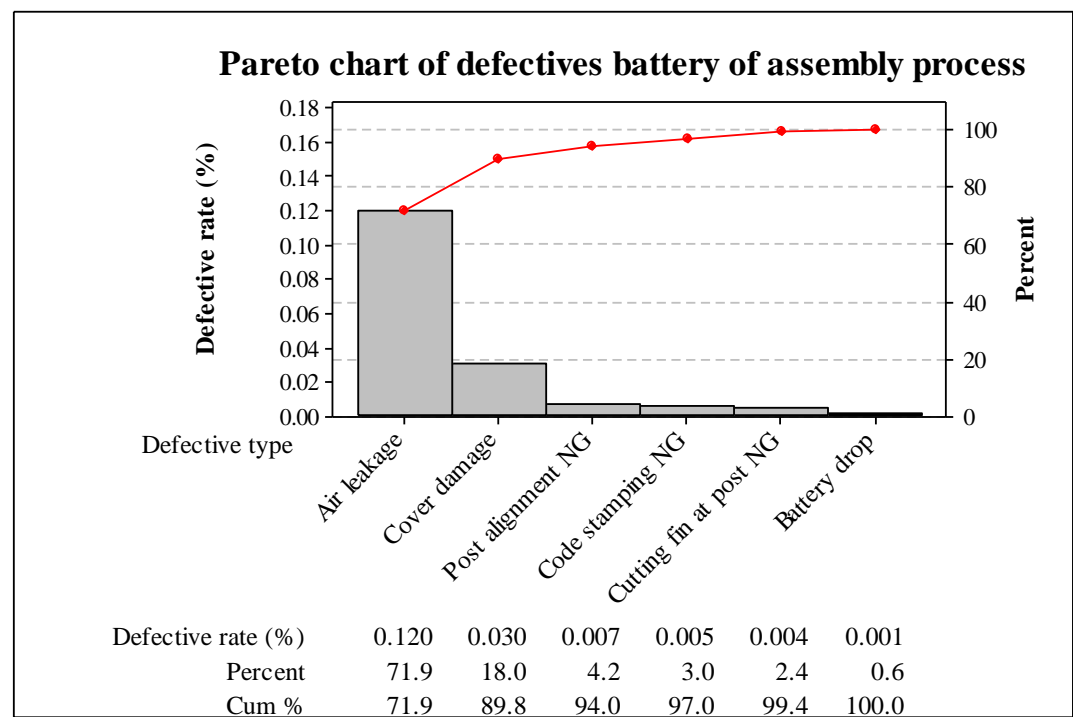

Fig.1 Pareto chart of defective batteries from the assembly process

\section{Dotplot of comparative seal strength}

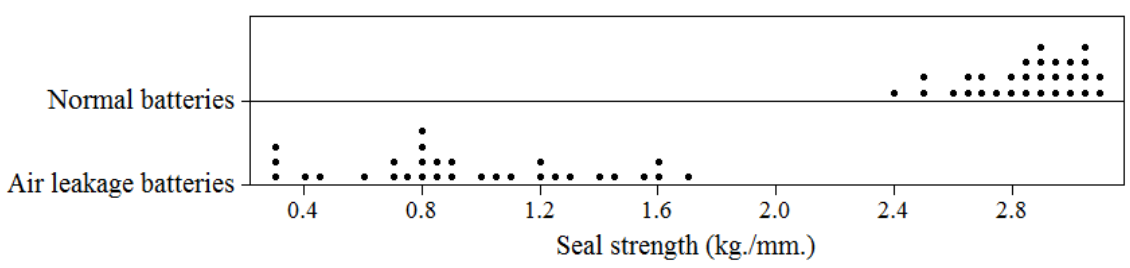

Fig.2 Comparative dot plots of seal strength between normal and air leakage batteries

\subsection{Experimental designs}

\section{METHOD}

\subsubsection{Screening experiment with two-level full factorial experimental design}

This research studied the effect of five factors on the seal strength. These factors were main factors related in the heat sealing process. These factors were the stopper distance of the case, the stopper distance of the lid, the heating plate temperature, the holding time while sealing the case and the lid, and the melting time. First, the experiments using the two-level full factorial design $\left(2^{5}\right)$ with a single replicate and three center points were performed to screen out the insignificant factors. The two-level factorial design provided a fewer number of runs for the screening purpose. The center points were added to check whether the curvature effect was presented. The two levels which were tested for each factor were determined from the bound of possible factor setting and from the literature review. The levels are shown in Table 1.

Table1 Factors and factor levels of the heat sealing process

\begin{tabular}{clcccc}
\hline \multirow{2}{*}{ Symbol } & \multicolumn{1}{c}{ Factors } & \multirow{2}{*}{ Unit } & \multicolumn{3}{c}{ Levels of Factors } \\
\cline { 4 - 5 } & & $\mathrm{mm}$ & 34.1 & Conter & High \\
\hline A & Stopper distance of case & mm. & 77.0 & 78.0 & 36.1 \\
B & Stopper distance of lid & degree Celsius & 325 & 330 & 79.0 \\
C & Heating plate temperature & second & 4.5 & 5.0 & 335 \\
D & Holding time & second & 2.5 & 3.0 & 3.5 \\
E & Melting time & & & & \\
\hline
\end{tabular}




\subsubsection{Response surface methodology with the face-centered central composite design}

After obtaining the significant factors from the screening experiment above, the Response Surface Methodology (RSM) was then used to find the equation of non-linear relationship between the response and the factors. Next, the optimal level of the significant factors was determined from the equation to maximize the seal strength of the VRLA battery. The face-centered central composite design was used instead of the spherical central composite design to avoid the experimental runs at the extreme settings. In addition, the face-centered CCD does not require as many center points as the spherical CCD [8].

\section{ANALYSIS OF RESULTS AND DISCUSSION}

\subsection{Analysis of results of the screening experiment}

The experimental data were analyzed using the Analysis of Variance (ANOVA) method. The significance level (p-value) of each main effect and interaction effect was shown in Table 2. It can be seen that the effects that were statistically significant at the significance level of 0.05 were the main effects of the stopper distance of the case (A), the stopper distance of the lid (B), and the melting time (E). The two-way interaction effect between the stopper distance of the case and the stopper distance of the lid (A*B) and also the curvature effect were found to be significant at the significance level of 0.05 . Factors $C$ and $D$, which were the heating plate temperature and the holding time were screened out. The remaining three significant factors were then further analyzed using the face-centered central composite design.

Table 2 ANOVA results of the two-level full factorial experimental design.

\begin{tabular}{lrrrrr}
\hline \multicolumn{1}{c}{ Source } & DF & \multicolumn{1}{c}{$\begin{array}{c}\text { Sum of } \\
\text { Square }\end{array}$} & $\begin{array}{c}\text { Mean } \\
\text { Square }\end{array}$ & F & $\begin{array}{c}\text { P - } \\
\text { Value }\end{array}$ \\
\hline Main Effects & 5 & 11.7012 & 2.3402 & 19.47 & 0.000 \\
Stopper distance of case (A) & 1 & 9.3420 & 9.3420 & 77.74 & 0.000 \\
Stopper distance of lid (B) & 1 & 1.3686 & 1.3986 & 11.64 & 0.003 \\
Heating plate temperature (C) & 1 & 0.0116 & 0.0116 & 0.10 & 0.759 \\
Holding time (D) & 1 & 0.3301 & 0.3301 & 2.75 & 0.115 \\
Melting time (E) & 1 & 0.6188 & 0.6188 & 5.15 & 0.036 \\
2-Way Interactions & 10 & 2.1009 & 0.2101 & 1.75 & 0.145 \\
Stopper distance of case*Stopper distance of lid (A*B) & 1 & 0.9079 & 0.9079 & 7.55 & 0.013 \\
Stopper distance of case*Heating plate temperature (A*C) & 1 & 0.4209 & 0.4209 & 3.50 & 0.078 \\
Stopper distance of case*Holding time (A*D) & 1 & 0.0893 & 0.0893 & 0.74 & 0.400 \\
Stopper distance of case*Melting time (A*E) & 1 & 0.2363 & 0.2363 & 1.97 & 0.178 \\
Stopper distance of lid*Heating plate temperature (B*C) & 1 & 0.0751 & 0.0751 & 0.62 & 0.440 \\
Stopper distance of lid*Holding time (B*D) & 1 & 0.0011 & 0.0011 & 0.01 & 0.924 \\
Stopper distance of lid*Melting time (B*E) & 1 & 0.1188 & 0.1188 & 0.99 & 0.333 \\
Heating plate temperature *Holding time (C*D) & 1 & 0.0639 & 0.0639 & 0.53 & 0.475 \\
Heating plate temperature *Melting time (C*E) & 1 & 0.0000 & 0.0000 & 0.00 & 0.988 \\
Holding time*Melting time (D*E) & 1 & 0.1876 & 0.1876 & 1.56 & 0.228 \\
Curvature & 1 & 3.6676 & 3.6676 & 30.52 & 0.000 \\
Residual Error & 18 & 2.1631 & 0.1202 & & \\
Lack of Fit & 16 & 2.1598 & 0.1350 & 82.65 & 0.012 \\
Pure Error & 2 & 0.0033 & 0.0016 & & \\
\hline Total & 34 & 19.6328 & & & \\
\hline
\end{tabular}

\subsection{Analysis of results of the RSM experiment}

The Analysis of Variance (ANOVA) was performed to the results obtained from the face-centered central composite design experiment. It was found that the all linear terms, all square terms, and all interaction terms of the three factors excluding BE interaction were significant at the significance level of 0.05 .

Table 3 ANOVA results of RSM and face-centered central composite design

\begin{tabular}{lcccrr}
\hline \multicolumn{1}{c}{ Source } & D & Sum of & Mean & \multirow{2}{*}{ F } & \multirow{2}{*}{ P - Value } \\
\hline Regression & F & Square & Square & \multicolumn{1}{c}{ S } & \\
Linear & 9 & 9.48190 & 1.05354 & 124.13 & $<0.0005$ \\
Stopper distance of case (A) & 3 & 0.52814 & 0.17605 & 20.74 & $<0.0005$ \\
Stopper distance of lid (B) & 1 & 0.42849 & 0.42849 & 50.59 & $<0.0005$ \\
Melting time (E) & 1 & 0.05476 & 0.05476 & 6.45 & 0.0290 \\
& 1 & 0.04489 & 0.04489 & 5.29 & 0.0440
\end{tabular}




\begin{tabular}{lrrrrr}
$\begin{array}{l}\text { Square } \\
\text { Stopper distance of case*Stopper distance of case }\end{array}$ & 3 & 8.75233 & 2.91744 & 343.74 & $<0.0005$ \\
(AA) & 1 & 7.09241 & 1.30928 & 154.26 & $<0.0005$ \\
$\quad$ Stopper distance of lid*Stopper distance of lid (BB) & 1 & 1.50152 & 0.97357 & 114.71 & $<0.0005$ \\
Melting time*Melting time (EE) & 1 & 0.15840 & 0.15840 & 18.66 & 0.0020 \\
Interaction & 3 & 0.20144 & 0.06715 & 7.91 & 0.0050 \\
$\quad$ Stopper distance of case*Stopper distance of lid & 1 & 0.14311 & 0.14311 & 16.86 & 0.0020 \\
(AB) & & & & & \\
$\quad$ Stopper distance of case*Melting time (AE) & 1 & 0.05281 & 0.05281 & 6.22 & 0.0320 \\
$\quad$ Stopper distance of lid*Melting time (BE) & 1 & 0.00551 & 0.00551 & 0.65 & 0.4390 \\
Residual Error & 10 & 0.08487 & 0.00849 & & \\
$\quad$ Lack-of-Fit & 5 & 0.08432 & 0.01686 & 153.31 & $<0.0005$ \\
\hline Total & 19 & 9.56678 & & & \\
\hline
\end{tabular}

The backward regression analysis was performed in order to find the equation of the relationship between the response and the significant experimental factors. The response surface model was shown in equation (1).

$$
\mathrm{Y}=3.105-0.207 \mathrm{X}_{\mathrm{A}}-0.074 \mathrm{X}_{\mathrm{B}}+0.067 \mathrm{X}_{\mathrm{E}}-0.690 \mathrm{X}_{\mathrm{A}}^{2}-0.595 \mathrm{X}_{\mathrm{B}}^{2}-0.240 \mathrm{X}_{\mathrm{E}}^{2}-0.134 \mathrm{X}_{\mathrm{A}} \mathrm{X}_{\mathrm{B}}+0.081 \mathrm{X}_{\mathrm{A}} \mathrm{X}_{\mathrm{E}}
$$

where:

$\mathrm{Y}=$ Seal strength $(\mathrm{kg} . / \mathrm{mm}$.

$\mathrm{X}_{\mathrm{A}}=$ Stopper distance of the case $(\mathrm{mm}$.

$\mathrm{X}_{\mathrm{B}}=$ Stopper distance of the lid (mm.)

$\mathrm{X}_{\mathrm{E}}=$ Melting time (second)

The model shown in equation (1) had the $\mathrm{R}^{2}$ of $99.11 \%$. This high value of $\mathrm{R}^{2}$ showed that this model can explain $99.11 \%$ of the variability in the data. Thus, this model was good enough to predict the relationship between the heat seal strength and the three factors.

\subsection{Optimization of factor levels}

The response surface model was solved to obtain the optimal levels of factors. The optimization result in Table. 4 and Fig. 3 showed that it was predicted that the maximum heat seal strength of $3.125 \mathrm{~kg} . / \mathrm{mm}$. could be obtained by setting the stopper distance of the case at $34.97 \mathrm{~mm}$., the stopper distance of the lid at $77.95 \mathrm{~mm}$., and the melting time at 3.1 seconds.

Table 4 Optimum factor levels and heat seal strength response

\begin{tabular}{lccc}
\hline Factors and Response & Symbol & Values & Unit \\
\hline Stopper distance of case & A & 34.97 & $\mathrm{~mm}$. \\
Stopper distance of lid & B & 77.95 & $\mathrm{~mm}$. \\
Melting time & E & 3.1 & second \\
\hline Heat seal strength & Y & 3.125 & $\mathrm{~kg} . / \mathrm{mm}$. \\
\hline
\end{tabular}

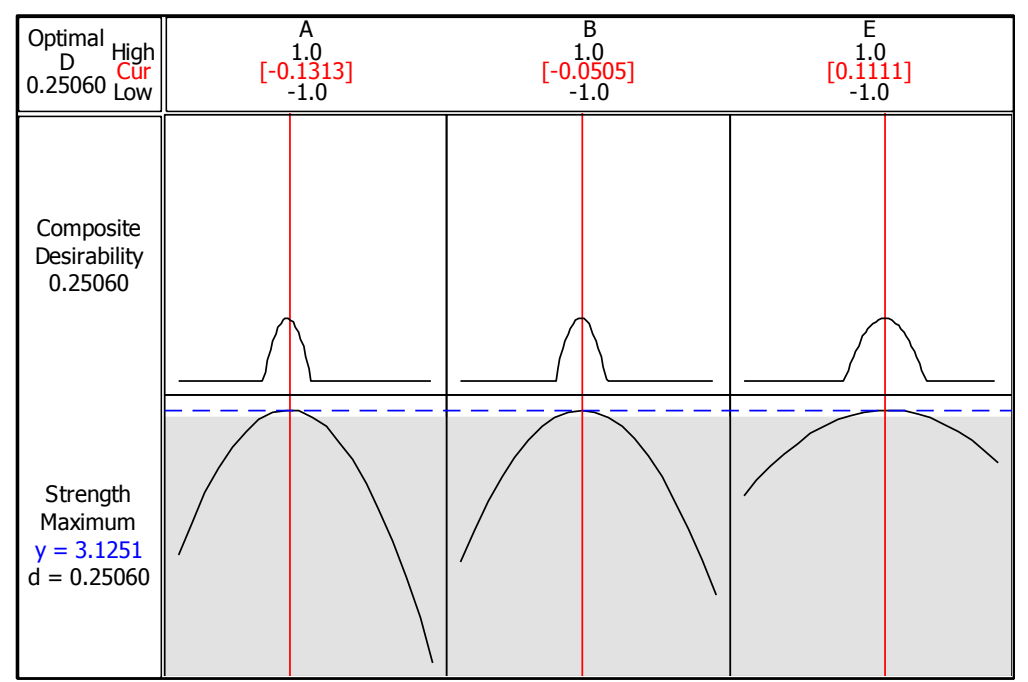

Fig.3 The optimization result of heat seal strength 
The results can be discussed as follows. The highest seal strength was obtained when the stopper distance of the case, the stopper distance of the lid, and the melting time were set around the middle values. In general, the seal strength was decreased as the stopper distance of the case and the lid were increased, and the melting time was decreased. The reason was that when the stopper distance was increased and the melting time was decreased, the polypropylene plastic was not melted enough to form a good bond between the plastic case and the lid. On the other hand when the stopper distance of the case and the lid were decreased, and the melting time was increased, the polypropylene plastic was over melted and then stick on the heating plate of the machine instead of sticking on the right position between the case and the lid. Thus, the good bond between the case and the lid was not obtained. Thus, the middle levels of these factors as shown in Table 4 were the optimal setting.

\subsection{Confirmatory results}

After implementing the new factor level setting at the heat sealing machine for three months, the average defective rate $(\%)$ of air leakage batteries was decreased from $0.12 \%$ to $0.01 \%$ as shown in Fig. 4.

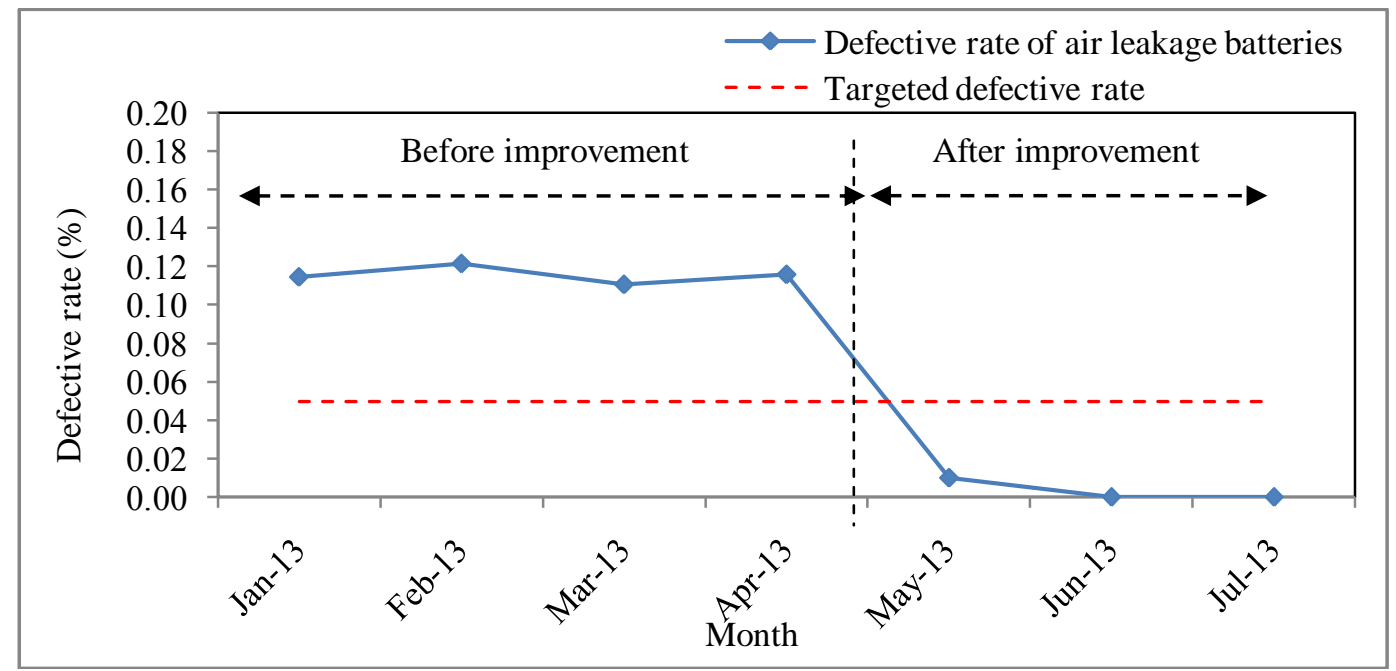

Fig.4 Comparative defective rates of air leakage batteries before and after improvement

\section{CONCLUSION}

This paper presented the statistical experiment design methodology to decrease the defective rate from air leakage of the VRLA battery. The screening experiment and the response surface methodology were applied to help identify the significant factors in the heat sealing process and indicate the optimal levels of those factors. It was found that the stopper distance of the case, the stopper distance of the lid, and the melting time are significant factors that affect the heat seal strength. The optimization technique helped indicate that the machine setting should be at the stopper distance of the case at $34.97 \mathrm{~mm}$., the stopper distance of the lid at $77.95 \mathrm{~mm}$., and the melting time at 3.1 seconds to maximize the heat seal strength.

After improvement, it was found that the defective rate from air leakage defect significantly decreased from $0.12 \%$ to $0.01 \%$, which is equal to $92 \%$ defective reduction.

\section{REFERENCES}

[1] A. Zabaniotou, E. Kouskoumvekaki, and D. Sanopoulos, Recycling of spent lead/acid batteries: the case of Greece. Resources, Conservation and Recycling, 25, 1999, 301-317

[2] R.M. Dell, Batteries fifty years of materials development. Solid State Ionics, 134, 2000, 139-158

[3] D.A.J. Rand, P.T. Moseley, J. Garche, and C.D. Parker, Valve-Regulated Lead-Acid Batteries. (Elsevier, Netherlands, 2004).

[4] E.E. Ferg and N. Rust, The effect of $\mathrm{Pb}$ and other elements found in recycled polypropylene on the manufacturing of lead-acid battery cases. Polymer Testing, 26, 2007, 1001-1014

[5] F.H. Su and H.X. Huang, Supercritical carbon dioxide-assisted reactive extrusion for preparation longchain branching polypropylene and its rheology. Supercritical Fluids, 56, 2011, 114-120

[6] N. Rust, E.E. Ferg, and I. Masalova, A degradation study of isotactic virgin and recycled polypropylene used in lead acid battery casings. Polymer Testing, 25, 2006, 130-139

[7] T. Puangpum and W. Tharmmaphornphilas, Battery leakage reduction by applying a six sigma approach. International Conference on Intelligent Manufacturing \& Logistics Systems, 8, 2012, 83-89

[8] D.C. Montgomery, Design and analysis of experiments. (John Wiley \& Sons, New York, 2013) 